\title{
Titanates and Titanate-Metal Compounds in Biological Contexts
}

\author{
Yen-Wei Chen ${ }^{1 *}$, Jeanie L. Drury ${ }^{1,2}$, Whasun Oh Chung ${ }^{2}$, David T. Hobbs ${ }^{3}$ and John C. \\ Wataha $^{1}$
}

${ }^{1}$ Department of Restorative Dentistry, University of Washington School of Dentistry, USA

${ }^{2}$ Department of Oral Health Sciences, University of Washington School of Dentistry, USA

${ }^{3}$ Savannah River National Laboratory, USA

*Corresponding author: Yen-Wei Chen, Department of Restorative Dentistry, University of Washington School of Dentistry, Seattle, 1959 NE Pacific St, WA 98195-7456, D770 Health Sciences Building, Box 357456, USA, Tel: (206) 543-5923, Fax: (206) 543-7783, E-mail: ywchen@uw.edu

\begin{abstract}
Metal ions are notorious environmental contaminants, some causing toxicity at exquisitely low (ppm-level) concentrations. Yet, the redox properties of metal ions make them attractive candidates for bio-therapeutics. Titanates are insoluble particulate compounds of titanium and oxygen with crystalline surfaces that bind metal ions; these compounds offer a means to scavenge metal ions in environmental contexts or deliver them in therapeutic contexts while limiting systemic exposure and toxicity. In either application, the toxicological properties of titanates are crucial. To date, the accurate measurement of the in vitro toxicity of titanates has been complicated by their particulate nature, which interferes with many assays that are optical density (OD)-dependent, and at present, little to no in vivo titanate toxicity data exist. Compatibility data garnered thus far for native titanates in vitro are inconsistent and lacking in mechanistic understanding. These data suggest that native titanates have little toxicity toward several oral and skin bacteria species, but do suppress mammalian cell metabolism in a cellspecific manner. Titanate compounds bind several types of metal ions, including some common environmental toxins, and enhance delivery to bacteria or cells. Substantial work remains to address the practical applicability of titanates. Nevertheless, titanates have promise to serve as novel vehicles for metal-based therapeutics or as a new class of metal scavengers for environmental applications.
\end{abstract}

\section{Keywords}

Biocompatibility, Cancer, Antibiotics, Drug-delivery, Environmental cleanup, Titanates and titanate-metal compounds

\section{Introduction}

Alkali metal titanates are a class of inorganic compounds that generally feature a layered structure in which the anionic titania layers are separated by exchangeable cations. One member of this class of compounds, monosodium titanate (MST), was first reported in the 1970's as an effective ion-exchange material in dilute acidic, neutral, and strongly alkaline solutions [1]. MST and other alkali titanates were developed to exploit their high affinity for some metal ions, making them attractive for separating ions of radioactive metals such as ${ }^{90} \mathrm{Sr},{ }^{238,239} \mathrm{Pu},{ }^{237} \mathrm{~Np}$ and ${ }^{235,238} \mathrm{U}$ from aqueous liquid wastes produced during the reprocessing of nuclear fuels [2]. More recently,
Table 1: Metals and metal compounds that are known to bind titanates

\begin{tabular}{|l|c|c|c|}
\hline Metals & Symbol $^{*}$ & Atomic \# & Atomic Weight \\
\hline Strontium & $\mathrm{Sr}$ & 38 & 87.62 \\
\hline Technetium & $\mathrm{Tc}$ & 43 & 98.0 \\
\hline Ruthenium & $\mathrm{Ru}$ & 44 & 101.1 \\
\hline Cadmium & $\mathrm{Cd}(\mathrm{II})$ & 48 & 112.14 \\
\hline Palladium & $\mathrm{Pd}(\mathrm{II})$ & 46 & 106.4 \\
\hline Cesium & $\mathrm{Cs}$ & 55 & 132.9 \\
\hline Cerium & $\mathrm{Ce}$ & 58 & 140.1 \\
\hline Europium & $\mathrm{Eu}$ & 63 & 152.0 \\
\hline Gadolinium & $\mathrm{Gd}(\mathrm{III})$ & 64 & 157.3 \\
\hline Platinum & $\mathrm{Pt}(\mathrm{II}), \mathrm{Pt}(\mathrm{IV})$ & 78 & 195.1 \\
\hline Gold & $\mathrm{Au}(\mathrm{III})$ & 79 & 197.0 \\
\hline Mercury & $\mathrm{Hg}(\mathrm{II})$ & 80 & 200.5 \\
\hline Uranium & $\mathrm{U}$ & 92 & 238.0 \\
\hline Neptunium & $\mathrm{Np}$ & 93 & 237.0 \\
\hline Plutonium & $\mathrm{Pu}$ & 94 & 244.0 \\
\hline & & & \\
\hline Metal Compounds & & & \\
\hline triethyl-phosphine gold(I) & $\mathrm{Auranofin}{ }^{\otimes}$ & & \\
\hline tetra-acetato-thioglucose & & & \\
\hline cis-[PtCl $\left.\left(\mathrm{NH}_{3}\right)_{2}\right]$ & cis-platin & & \\
\hline & & & \\
\hline
\end{tabular}

*Ions shown where known

The list above may not be inclusive [2,3].

titanates have been investigated for possible utility in medicine and environmental sciences via binding other metal ions, including $\mathrm{Au}(\mathrm{III}), \mathrm{Cd}(\mathrm{II}), \mathrm{Gd}(\mathrm{III}), \mathrm{Hg}(\mathrm{II}), \mathrm{Pd}(\mathrm{II}), \mathrm{Pt}(\mathrm{II}), \mathrm{Pt}(\mathrm{IV})$, as wells as some metal-organic compounds (Table 1) [3]. Other alkali metal ions have not been fully explored. However, titanates complexes with these ions may be possible, depending on various factors including but not limited to the valency and the solubility of the ion of interest.

The particle size and morphology of the titanates depends on synthetic conditions. MST has a roughly spherical morphology with an amorphous core and a nanocrystalline fibrous surface. It is produced by a sol-gel process in which the temperature, reagent concentrations and addition rates are controlled (Figure 1) [2]. The

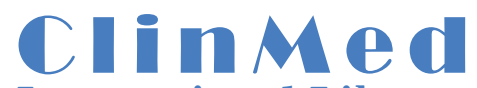

International Library

Citation: Chen YW, Drury JL, Chung WO, Hobbs DT, Wataha JC (2015) Titanates and Titanate-Metal Compounds in Biological Contexts. Int J Med Nano Res 2:009

Received: April 20, 2015: Accepted: June 10, 2015: Published: June 13, 2015

Copyright: ( 2015 Chen YW. This is an open-access article distributed under the terms of the Creative Commons Attribution License, which permits unrestricted use, distribution, and reproduction in any medium, provided the original author and source are credited. 

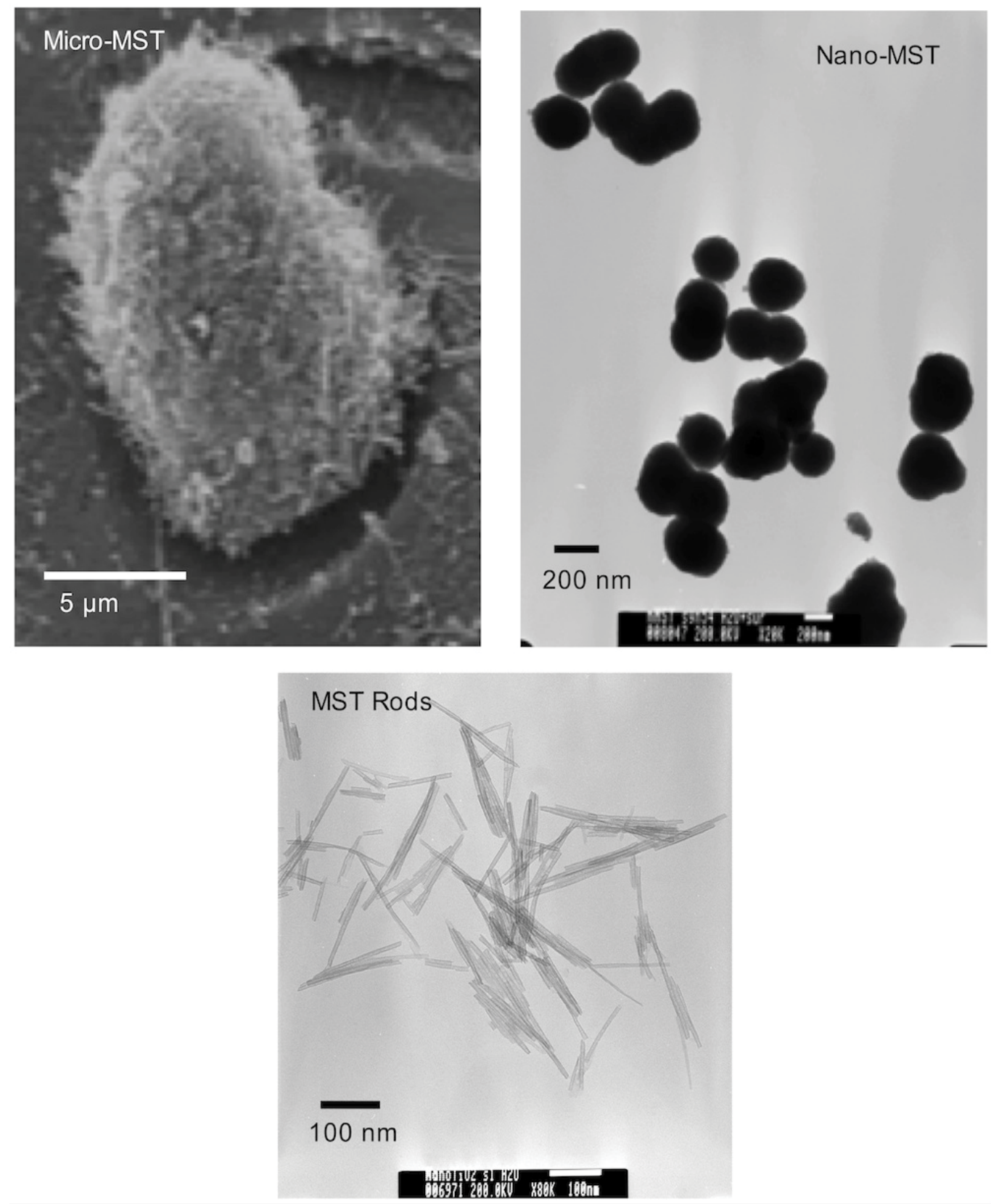

Figure 1: Scanning electron images of monosodium titanates (MST) in micro-sized spheres (upper left), nano-sized spheres (upper right), and nano-sized rods (lower). Micro-spheres have a crystalline surface phase, approximately 500nm thick, giving the spheres a 'fuzzy' appearance. The crystalline surface encases an amorphous core.

addition of surfactants and more dilute reagent concentrations can produce smaller particles in the nanosize range that feature much higher surface areas [4]. These nanosize particles were developed with a hope of increasing the adsorptive capacity and rate for metal ions. Nanosize sodium titanates with tubular shapes having lengths of 100-200nm and diameters of $<10 \mathrm{~nm}$ have been also been synthesized [4]. The sodium titanate nanotubes (NaTONT) are prepared by a hydrothermal reaction with titanium dioxide (anatase) and sodium hydroxide.

In addition to particle size and shape, the chemistry of the crystalline surface is a primary determinant of titanate-metal binding. This crystalline surface has been described as giving the titanates a 'fuzzy' appearance in scanning electron images [2] (Figure 1); the crystalline domain is highly porous and extends about $500 \mathrm{~nm}$ into the bulk of the micro-particles. The original titanates were monosodium titanates (MST, $\mathrm{HNaTi}_{2} \mathrm{O}_{5} \cdot x \mathrm{H}_{2} 0$ ) with a Ti-O or Ti-OH binding domain on the crystalline surface; More recently, peroxotitanates (APT, $\mathrm{H}_{v} \mathrm{Na}_{w} \mathrm{Ti}_{2} \mathrm{O}_{5} \cdot \mathrm{xH}_{2} \mathrm{O}\left[y \mathrm{H}_{z} \mathrm{O}_{2}\right], v+w=2$ and $z=0-2$ ) have been synthesized, whereby binding is believed to be mediated through the Ti-O-OH moiety as well as Ti-O and Ti-O-O moieties [3]. MST exhibits a white color similar to titanium dioxide, whereas the peroxotitanates are bright yellow characteristic of the $\mathrm{Ti}-\mathrm{O}-\mathrm{OH}$ species. In strongly alkaline solutions, the APT materials generally exhibit faster sorption rates compared to sodium titanates, which is likely due to increased surface area and the additional binding sites [3].

A variety of transition metal titanates can be prepared by exchanging the sodium ions for the transition metal. The extent of metal ion exchange depends largely on the metal ion (i.e., sorbate) concentration in solution, the $\mathrm{pH}$ of the solution and the ratio of the metal ion to the sodium titanate (i.e., phase ratio) [2]. As might be expected, high sorbate concentrations and phase ratios increase the extent of ion exchange toward the theoretical capacity based on the total quantity of exchange cations. It is important to note that the theoretical capacities for metal binding (for MST about 5.0 mequiv/g may not be reached; actual binding is markedly influenced by the binding solution. For example, Cd(II) will load to about $70 \%$ of the theoretical capacity in water, but only to about $45 \%$ in a phosphate- 


\section{Effect of MST on THP1 Monocyte Metabolism}

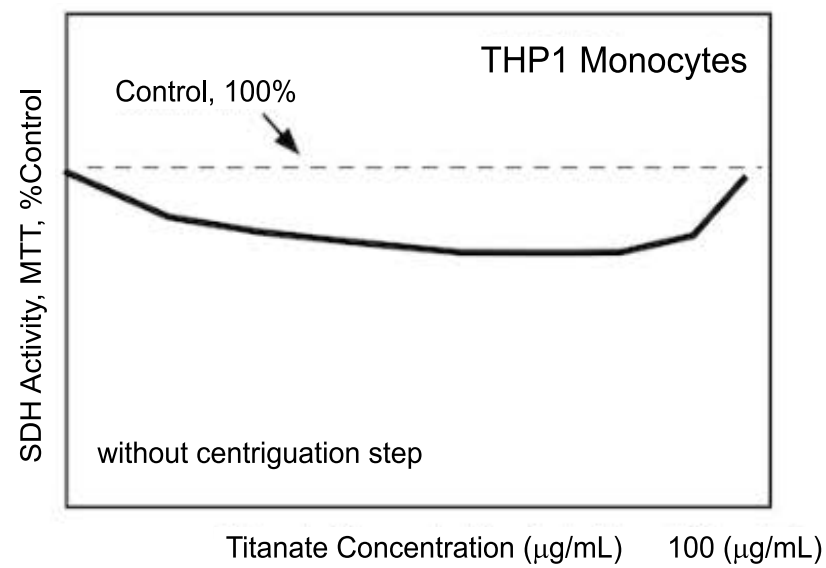

\section{Effect of Centriguation on OD Interference}

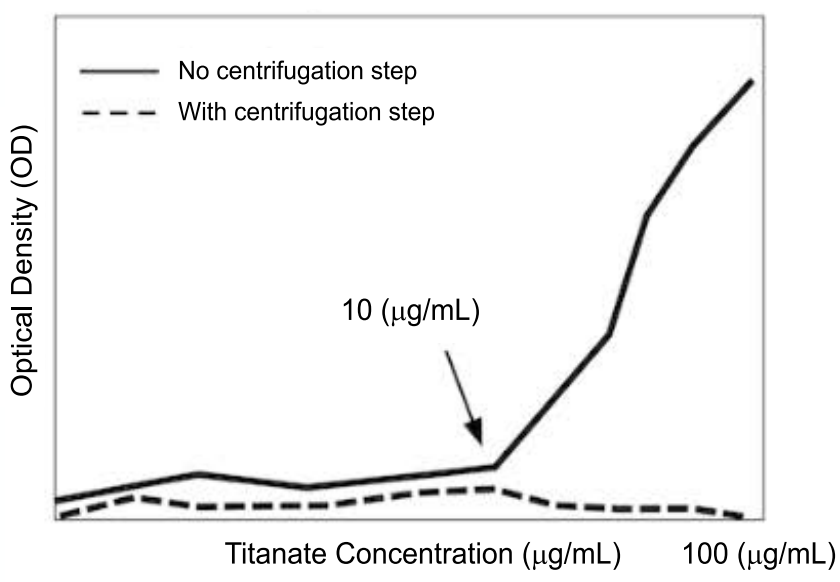

Effect of MST on L929 Fibroblast Metabolism

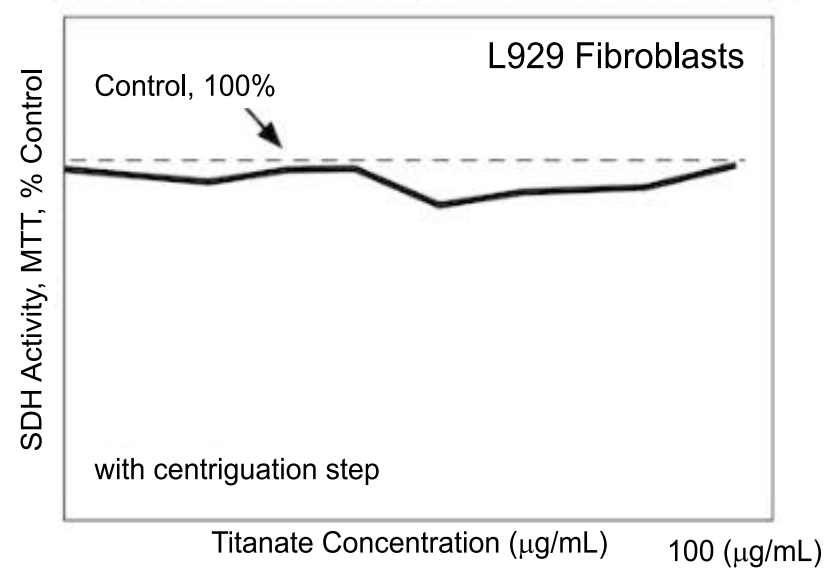

Figure 2: Early studies that measured the effects of monosodium titanate (MST, micro-sized) on the metabolism of mouse fibroblasts (L929) or human monocytes (THP1) revealed that the particulate nature of the MST interfered with the optical density (OD) used to measure succinate dehydrogenase (SDH) activity of the cells (upper). In experiments with no cells, centrifugation prior to transfer of the supernatant and a final OD reading reduced the interference (lower left), especially at higher MST concentrations. Experiment with cells (lower right) suggested that the interference was reduced using this strategy [2,12].

buffered saline (PBS) solution [2]. The reduced binding in the PBS solution is likely due to complexation of the Cd(II) ions with chloride and phosphates that behave differently than that of the aquo ion $\left(\mathrm{Cd}\left(\mathrm{H}_{2} \mathrm{O}\right)_{6}{ }^{2+}\right)$, which is the predominant species in aqueous solutions without high concentrations of complexants [2].

The extent of ion exchange also is dependent on the metal ion charge and the solution $\mathrm{pH}$ [2]. In general, sodium titanates exhibit higher affinity for metal ions that are more highly charged (e.g., $\mathrm{M}^{3+}$ ) than those with lower charge $\left(e . g ., \mathrm{M}^{2+}\right)$. Furthermore, the exchange of metal ions decreases with a decrease in $\mathrm{pH}$ (i.e., more acidic). This decrease occurs because of competition between the metal ion and the proton for binding sites on the titanate. Competition among protons, sodium ions, and metal ions with titanate binding sites makes delivery of metal ions plausible (particularly Au (III)) in biological conditions such as inflammation where $\mathrm{pH}$ is lower.

\section{Effects of Titanate Complexes on Mammalian Cells}

Prior to 2006, the biological effects of titanates were not known. Because many metal ions cause severe systemic toxicity, [5] the initial premise was that if metal ions could be delivered by titanates and sequestered locally, the risks of systemic toxicity from metal ions could be greatly reduced. Such strategies might be useful in treating cancer, inflammation, or bacterial infections, where metal ions have known therapeutic potential, [6-11] but mostly unrealized because of concerns about host toxicity. These ideas required that the biological effects of titanates themselves be investigated.

Initial studies of the biological effects of native particles (without metals), [2] exposed mammalian (human) monocytic cells (THP1) in vitro to MST (monosodium titanate) particles for 24-72 h, using mitochondrial (MTT) or monocytic secretory (TNFa) activities as indicators of cell response. Monocytes were chosen because it was thought that the particulate nature of the titanates might trigger secretion of inflammatory cytokines. Minor cytotoxic effects, but no secretory changes, were observed in these initial studies. However, an unusual 'cytotoxic reversal' was observed, where the suppression of cell metabolism by the particles was reduced at higher titanate concentrations. The authors suspected that an artifact in the measurement process caused this reversal (Figure 2).

Subsequent toxicity studies focused on both THP1 monocytes and murine fibroblasts (L929), using MST as well as the newly developed peroxo-titanates (APT), while simultaneously attempting to account for the 'cytotoxic reversal'. The authors hypothesized that the titanates, as particulates, were adding to the optical density (OD) used to estimate the mitochondrial activity, a suspicion that was confirmed using cell-free experiments [12]. To mitigate this artifact, a centrifugation-transfer step was employed prior to measurement of OD. Using this strategy, neither APT nor MST caused suppression of L929 or THP1 mitochondrial activity and furthermore, APT showed no tendency to alter TNFa secretion from THP1. These early experiments led to the assumption that native titanates had few biologic effects on cells (Figure 2).

From these initial studies, efforts turned to evaluating the biological effects of compounds of titanates and metal ions. By exposing L929 and THP1 cells to APT combined with a variety of metal ions or compounds (Gd(III), $\mathrm{Hg}(\mathrm{II}), \mathrm{Pd}(\mathrm{II}), \mathrm{Pt}(\mathrm{IV})$, cis-platin) 


\section{Effect of APT-metal Compounds on L929} Fibroblast Metabolism

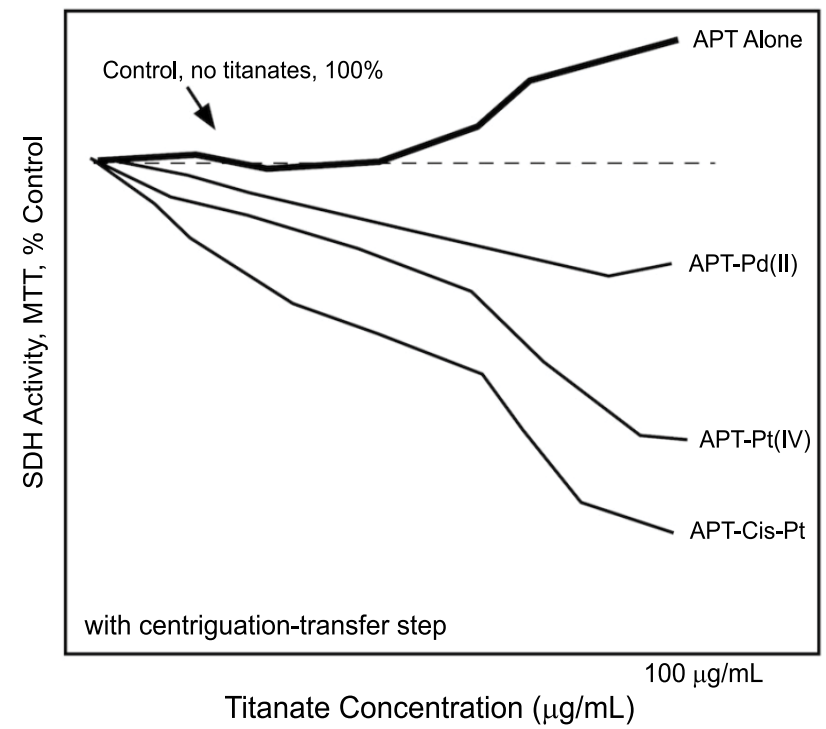

Figure 3: Studies of titanates have demonstrated that some titanate-metal compounds suppress cell-metabolism more than titanates alone, suggesting that the metal ion reaches the cell to cause suppression. Here, micro-sized peroxo-titanates (APT) complexed with $\mathrm{Pd}(\mathrm{II}), \mathrm{Pt}(\mathrm{IV})$, or cis-platin (cis-Pt) suppressed cellular succinate dehydrogenase (SDH) activity. Evidence supports the hypothesis that the effects of the metal are not mediated through extracellular dissociation of the metal from the titanate, but rather through some type of interaction between the APT-metal complex and the cells, as yet undefined. However, later results showed that the centrifugation transfer steps could not fully eliminate interference by APT particles. This problem led to the development of the cell-titer blue procedures. See references 3 and 16 , or 'Measuring the biological effects of titanates' section of this manuscript.

[3], the authors demonstrated that unlike native titanates, titanatemetal compounds significantly suppressed L929 metabolism (Figure 3). By estimating the quantity of metal ions that might be available to the cells from the titanate-metal compounds and comparing the effects of the titanate-metal compounds with those of metal ions alone, the authors concluded that the titanate-metal compounds were facilitating 'delivery' of the metal ions to L929 fibroblasts in some fashion (Figure 3) [3]. Substantial differences in the behavior of different titanate-metal compounds were reported; cis-platin was the most potent compound, followed by compounds with $\mathrm{Pt}(\mathrm{IV})$, $\mathrm{Gd}(\mathrm{III}), \mathrm{Hg}(\mathrm{II})$, and $\mathrm{Pd}(\mathrm{II})$ [3]. These differences were attributed to the differences in the toxicities of the metal ions themselves, but also a difference in how different titanate-metal compounds might interact with cells. In spite of the titanate-metal induced suppression of fibroblasts, monocytic cells showed no such effect; no suppression of THP1 was observed after exposure to any titanate-metal compound. These results, for both L929 and THP1 cells, were extended to Au(III) and a gold-organic compound previously used to treat arthritis (Auranofin") in a subsequent study [13].

Several years later, in a more detailed study, [14] THP1 monocytes were exposed to APT-metal compounds, but using cytokine secretion (IL6, IL1 $\beta$, and TNF $\alpha$ ) as a measure of cellular effect $[3,13]$. The hypothesis was that titanate-metal compounds might alter monocytic secretory behavior in spite of their low cytotoxicity. APT compounds with $\mathrm{Au}(\mathrm{III})$, Auranofin $^{\circledR}, \mathrm{Pd}(\mathrm{II}), \mathrm{Pt}(\mathrm{IV})$ and cis-platin had no effect on the nominal, near-zero baseline secretion of IL6, IL1 $\beta$, or TNF $\alpha$; i.e., these compounds did not induce secretion by themselves. However, when monocytes were activated by bacterial lipopolysaccharide after exposure to the titanate-metal compounds, significant enhancement of cytokine secretion was observed, depending on the titanate-metal compound and its concentration. The authors also reported that the $\mathrm{APT}-\mathrm{Au}(\mathrm{III})$ compounds released no detectable free $\mathrm{Au}(\mathrm{III})$ over 21 $\mathrm{d}$, further supporting the hypothesis that titanate-metal compounds acted by interacting as a compound with cells versus by releasing the ion prior to cell interaction.

A comprehensive study of the effects of APT- and MST-metal
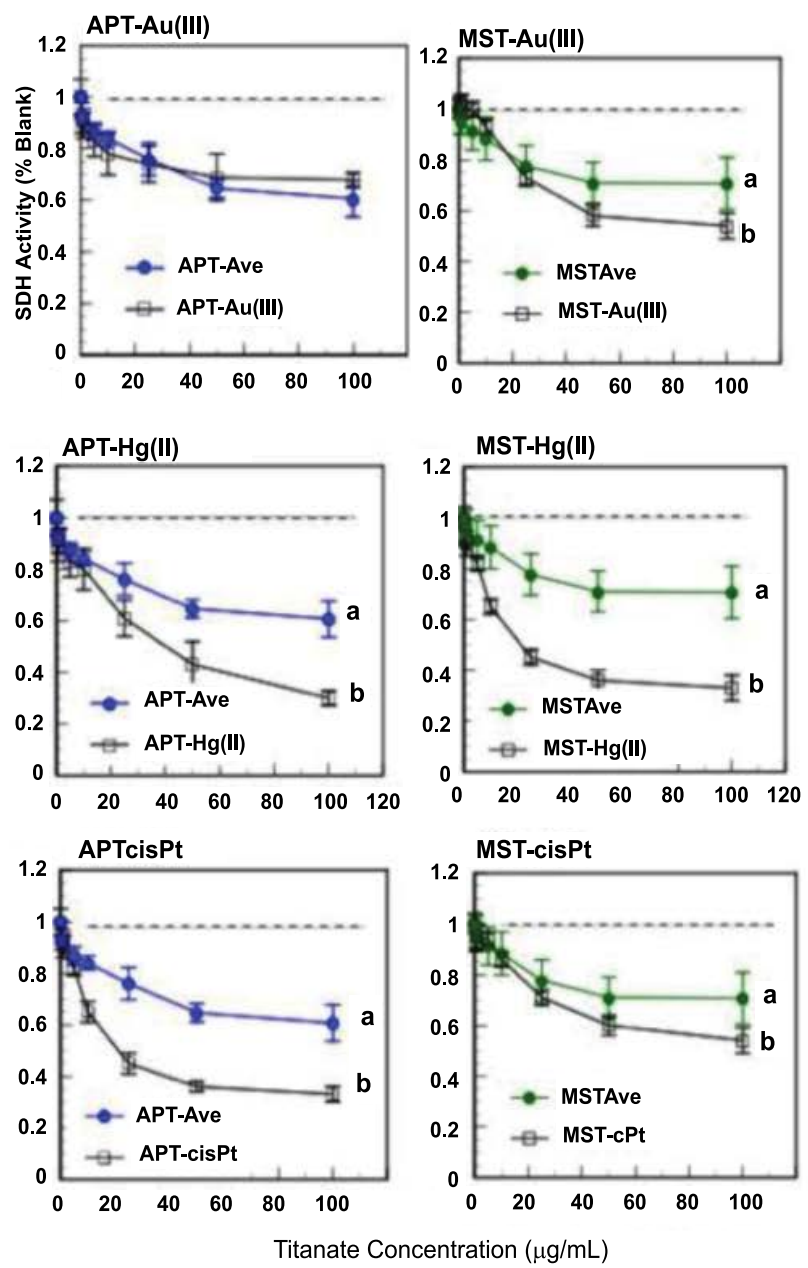

Figure 4: In contrast to early studies with L929 fibroblasts and THP1 monocytes, titanates alone (APT-average, left; MST-average, right) suppressed the succinate dehydrogenase (SDH) activity of some cell types such as oral squamous-cell carcinoma (OSC2) cells. As with other cell types, suppression was enhanced by some metal ions (here $\mathrm{Au}(\mathrm{III}), \mathrm{Hg}(\mathrm{II})$, and cisplatin). Lower-case letters indicate statistical differences within each graph (ANOVA, Tukey ad-hoc analysis, $\alpha=0.05, n=8$ ). The degree of suppression depended on the metal ion and the type of titanate. Figures adapted from reference [15]

compounds on an oral cancer cell line also has been reported [15]. In this work, oral squamous-cell carcinoma cells (OSC2) were exposed for $72 \mathrm{~h}$ in vitro to APT or MST compounds with $\mathrm{Au}(\mathrm{III}), \mathrm{Hg}(\mathrm{II})$, $\mathrm{Pd}(\mathrm{II}), \mathrm{Pt}(\mathrm{II})$, cis-platin, or $\mathrm{Pt}(\mathrm{IV}))$, and cell response measured via the adjusted MTT assay (with centrifugation-transfer, see above discussed and reference) [12]. The most notable observation of this work was that APT and MST suppressed, in native form, the mitochondrial activity of the OSC 2 cells by $35-40 \%$ vs. untreated controls (Figure 4) [15]. This observation was in contrast to other cells (L929 or THP1) where little or no suppression had been reported. The cytotoxicity of the native titanates was initially attributed to the rapid growth rate of the OSC2 cells $v s$. L929 or THP1 (Figure 4). As in previous studies, titanate-metal compounds further suppressed cell metabolism, supporting the biodelivery of metals hypothesis. Substantial differences between the effects of APT and MST compounds were observed. For APT, cis-platin and $\mathrm{Hg}$ (II) were the most potent suppressors of cell metabolism; for MST, the effects were more muted, but $\mathrm{Hg}$ (II) was the most potent. In this study, the authors reported results from a pilot scanning electron microscopic experiment in which the titanates were seen attaching to the cells; this was the first direct evidence of cell-titanate interactions [15].

Substantial improvements in the means by which the effects of titanates are measured have recently been investigated [16].Via a number of meticulously control experiments, the interfering nature of the titanate particulates in the traditional MTT assay, even with centrifugation, has been demonstrated (see section below, Figure 5). The most important 

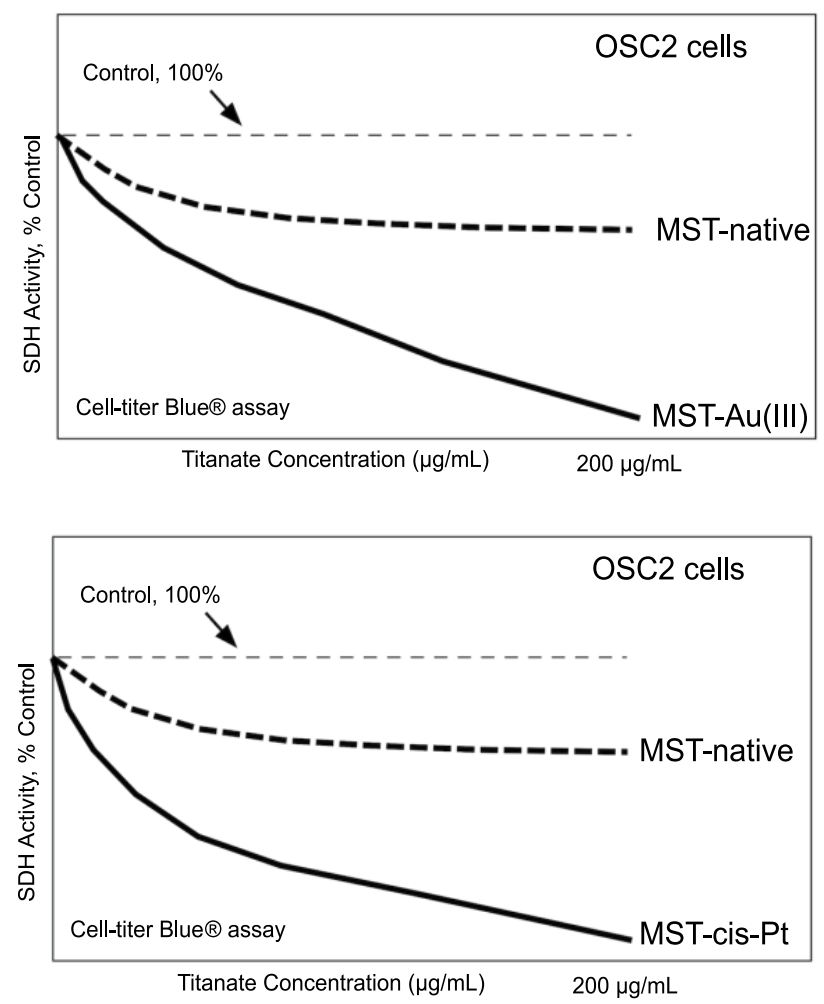

Figure 5: Use of the fluorescence-based CellTiter-Blue ${ }^{\circledR}$ assay (vs. an optical density-dependent assay) to measure succinate dehydrogenase (SDH) activity eliminated interference of the titanate particles and allowed higher concentrations of titanates to be tested (here up to $200 \mu \mathrm{g} / \mathrm{mL}$ ). The effects of MST-Au(III) and MST-cis-Pt (cis-platin) on oral squamous cell carcinoma (OSC2) cells were greater than evident with MTT-based assays (see figure 4 , MST results) that measured succinate dehydrogenase $(\mathrm{SDH})$ activities of cells using absorption (OD) [16].

consequence of these experiments is that the MTT assay likely generally underestimates the effects of titanates or titanates-metal compounds on cells. A fluorescence-based assay for mitochondrial function (CellTiterBlue), un-affected by particulates, was used to assess the effects of MST, MST-metal compounds (Au(III), cis-platin), Pt(IV)), and nano-MST particles [16]. Using OSC2 and diploid fibroblast (WI-38) cell types, this study reported that suppression of cellular mitochondrial function by native titanates was not restricted to rapidly growing cells; WI-38, which have a far slower growth rate than OSC2, were also suppressed $30-40 \%$ by MST. The enhanced suppression of cellular metabolism by titanate-metal compounds over native titanates also was reported, but in general, the effects of the metals were greater than previously reported using the MTT assay $[12,13]$. The effects of the nano-MST particles and its $\mathrm{Au}$ (III) compounds were more complex, but followed similar general trends [16].

\section{Effects of Titanate Complexes on Bacteria}

Many metal ions inhibit bacterial growth, but systemic exposure of humans to metal ions carries the risk of substantial toxicity. Because of this, metal ions have long been deemed unsuitable for therapeutic use against bacterial infection. However, titanate-metal compounds have emerged as a promising new class of antimicrobials against oral and skin bacterial infections. Titanate particles bind and sequester a variety of metals with high affinity, thus would be able to deliver metals to a site of infection with less systemic toxicity [14]. To assess the utility of metal titanate compounds against bacteria, studies first focused on the effects of native titanates and metal ions alone, then investigated the ability of titanate-metal compounds to inhibit bacterial growth.

In initial studies, neither native MST nor native APT suppressed bacterial growth (Ref. 17 and unpublished observations). The bacterial species tested included: oral periodontal pathogens Porphyromonas gingivalis, Aggregatibacter actinomycetemcomitans and Prevotella

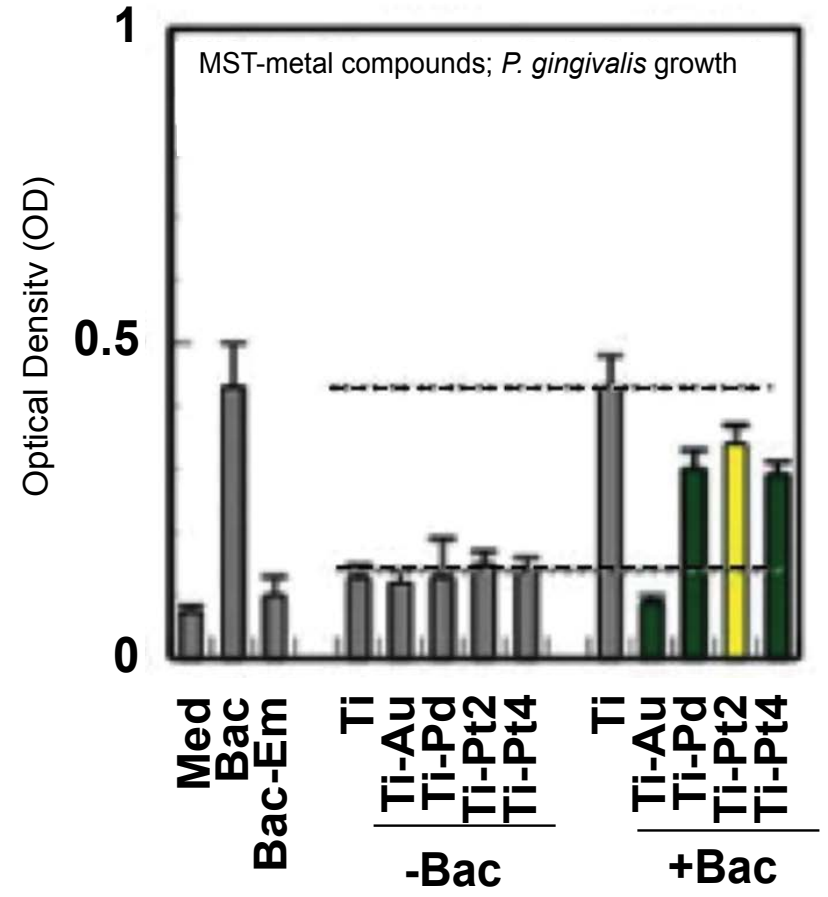

Figure 6: Titanates have been shown, when compounded with some metal ions such as $\mathrm{Au}(\mathrm{III}), \mathrm{Pd}(\mathrm{II}), \mathrm{Pt}(\mathrm{II})$, or $\mathrm{Pt}(\mathrm{IV})$ to suppress the growth of oral bacteria such as $P$. gingivalis, a periodontal (oral inflammatory disease) pathogen. Many controls are needed in these types of experiments such as the optical density $(\mathrm{OD})$ of the culture medium $(\mathrm{Med})$, the bacteria alone $(B a c)$, bacteria treated with the antibiotic erythromycin $(B a c-E m)$, as well as the various titanate-metal compounds without bacteria $(-B a c)$. Titanates alone did not suppress growth of $P$. gingivalis $(T i)$ but suppressed growth depending when complexed with some metal ions [17].

intermedia; cariogenic oral bacteria Streptococcus mutans and Actinomyces naeslundii; Fusobacterium nucleatum, a bridging oral organism between pathogens and non-pathogens; pathogenic skin bacteria Staphylococcus aureus and Streptococcus pyogenes; and nonpathogenic skin bacteria Streptococcus epidermidis.

Contrary to native titanates, metal ions (alone) inhibited growth of bacteria in a species-specific manner, varying depending on metals and different species of bacteria tested (Figure 6). For example, growth of $A$. naeslundii, a bacterial species implicated in tooth root surface caries (tooth decay) and early childhood caries, was inhibited by $\mathrm{Au}(\mathrm{III})$ at concentrations as low as $10 \mu \mathrm{M}$, but uninhibited by $\mathrm{Pt}(\mathrm{IV})$ at concentrations $\leq 750 \mathrm{mM}$ [17]. Similarly, exposure of $S$. mutans, a bacteria known to cause dental caries, to $\mathrm{Au}(\mathrm{III})$ at the concentrations of 1-20 $\mu \mathrm{M}$ decreased bacterial growth, with little difference shown between different concentrations tested.

Titanate-metal compounds have been reported to inhibit bacterial growth, depending on the type of metal ion and the bacterial species (Figure 6) [17].An inhibitory effect was observed with MST compounds of $\mathrm{Au}(\mathrm{III}), \mathrm{Pt}(\mathrm{IV})$ or $\mathrm{Pd}(\mathrm{II})$ ions [17]; the degree of inhibition varied among metals and bacterial species, but MST-Au(III) showed the greatest effect. Growth of A. actinomycetemcomitans, F. nucleatum and $P$. gingivalis was suppressed by $\geq 50 \%$ between concentrations of $1-10 \mu \mathrm{g} / \mathrm{mL}$, whereas the growth suppression for A. naeslundii started at $50 \mu \mathrm{g} / \mathrm{mL}$. Unlike other bacteria, $P$. intermedia growth was not affected by MST-Au(III) complexes up to $1500 \mu \mathrm{g} / \mathrm{mL}$. Compared to MST-Au(III), APT-Au(III) was less effective in inhibiting bacterial growth. For example, maximum bacterial growth suppression on $A$. actinomycetemcomitans and F. nucleatum was reduced from $100 \%$ down to $10 \%$ and $40 \%$, respectively, for APT-Au(III) compared to MST-Au(III) [17]. Similarly, growth of A. naeslundii was suppressed up to $80 \%$ in the presence of MST-Au(III), while APT-Au(III) did not suppress growth of A. naeslundii [17]. APT-Au(III) also showed inhibitory effect against $S$. mutans at $20 \mu \mathrm{g} / \mathrm{mL}$, but MST-Au(III) was more effective against growth of $S$. mutans at lower concentrations starting at $1.25 \mu \mathrm{g} / \mathrm{mL}$ (unpublished observations). 
a)

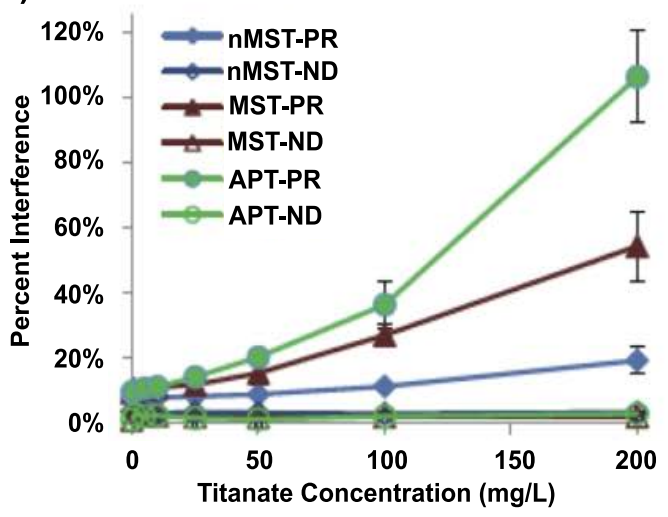

b) MST Interference at $200 \mathrm{mg} / \mathrm{L}$

c)

nMST Interference at $200 \mathrm{mg} / \mathrm{L}$
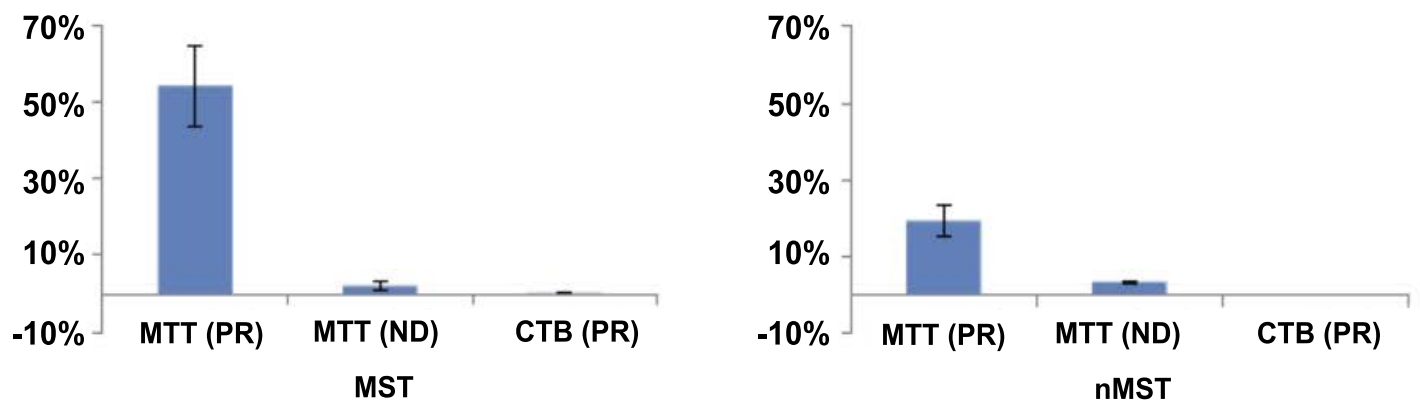

Figure 7: When working with particulate titanates, substantial interferences can confound biological assays that depend on optical density for measuring the effects of titanates on cell metabolism in vitro. The degree of interference depended on the type of titanate (peroxo-titanate, APT; monosodium titanate, MST; nano-sized MST, nMST). Three types of assays have been used to assess cell metabolism: the traditional plate reader $(P R)$, the NanoDrop ${ }^{\circledR}(N D)$ method, and the CellTiter-Blue ${ }^{\circledR}(C T B)$ method. Of these, the CTB method had the lowest risk of interference, likely because it is a fluorescence-based assay and is less altered by changes in optical density [16].

Other titanate-metal compounds were less universal than $\mathrm{Au}(\mathrm{III})$ in suppressing bacterial growth. No inhibition of bacterial growth was observed by MST-Pd(II) and MST-Pt(IV) at up to $1500 \mu \mathrm{g} / \mathrm{mL}$ [17]. Although $\mathrm{Au}(\mathrm{III})$ showed more robust inhibition of bacterial growth when coupled with MST than APT, Pd(II) and Pt(IV) coupled with APT showed greater inhibition of growth of $P$. gingivalis, $A$. actinomycetemcomitans and $F$. nucleatum, than when coupled with MST [17]. In particular, all three metals coupled with APT titanates showed $100 \%$ suppression of $P$. gingivalis growth compared to titanate-only controls [17]. APT-Pt(IV) also inhibited growth of $S$. mutans, with $>50 \%$ of bacterial growth inhibited by $12 \mathrm{~h}$. Similarly, APT-Pt(II) had an inhibitory effect at 10 and $20 \mu \mathrm{g} / \mathrm{ml}$ starting at $8 \mathrm{~h}$, but little change in the inhibitory effect of APT-Pt(II) was observed at 10 and $12 \mathrm{~h}$ (unpublished observations). Collectively, these results support the antibacterial potential of titanate-metal complexes at metal concentrations 2- to 375-fold lower than metal ions alone, suggesting titanates could be an effective delivery vehicle for metal ions as antibacterial therapeutics [17].

The inhibition of the growth of skin bacteria by metal titanates was less robust than for oral bacteria. Minimal suppression was observed on growth of skin pathogen $S$. aureus and non-pathogen S. epidermidis for all APT- and MST-metal compounds (Au(III), $\mathrm{Pd}(\mathrm{II})$, or $\mathrm{Pt}(\mathrm{II}))$. The growth of another skin pathogen $S$. pyogenes, a causative agent of impetigo and necrotizing fasciitis, was mildly inhibited by APT-metal compounds. Compared to the control bacteria exposed to titanates alone, growth of $S$. pyogenes was reduced by $13 \%, 16 \%$ and $20 \%$ when exposed to APT-Pd(II), APT-Pt(II) and APT-Au(III), respectively (unpublished observations). These results emphasize the metal-specific and bacteria-species-specific nature of titanate metal compounds against bacterial growth. Further research is needed in this area.

\section{Measuring the Biological Effects of Titanates}

Initial tests of the biological effects of titanates on mammalian cells and bacteria used assays that relied on optical density (OD) measurements. Due to the particulate nature of titanates and their apparent 'stickiness' to cells and culture vessels, it was suspected early on that particles in solution and on culture substrates interfered with OD measurements, resulting in greater OD than appropriate (Figure 2,7,8). After considerable investigation, it is now known that the degree to which these false signals affect the overall results is highly dependent on the initial titanate concentration, the size of the titanates (e.g., nano vs. micro), and the affinity of the titanate to the culture vessel. These results demonstrate the importance of considering artifacts when working with insoluble phases in biological assays. Similar optical density interference concerns have been discussed extensively for particulates in biological assays [18].

Various strategies have been employed to try to mitigate these false signals. As previously mentioned (see Effects of titanate complexes on mammalian cells) initial strategies included centrifugation of 96-well plates followed by the transfer of the MTT-formazan supernatant [12]. The optical density of the supernatant was then read using a standard plate reader. The hope was that the centrifugation would remove the titanates from the supernatant, with transfer assuring an unbiased OD reading. Tests in cell-free systems showed that without this correction MST and APT altered the apparent MTT product by $\sim 25 \%$ at concentrations up to $100 \mu \mathrm{g} / \mathrm{mL}$ (Figure 2) [12]. These results have been confirmed by more recent experiments [16], where titanate 


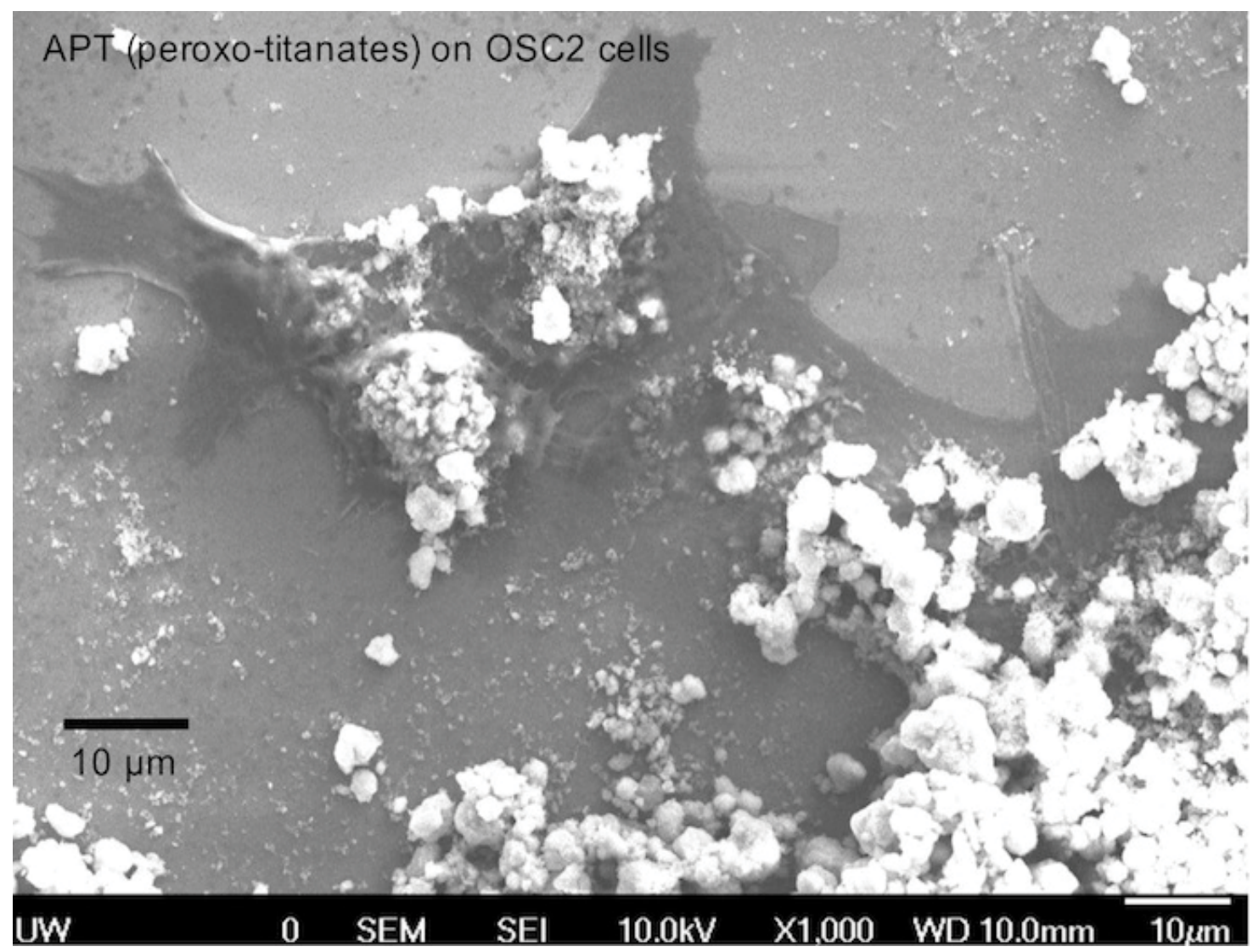

Figure 8: Titanates appear to have some affinity for cells and culture vessels; the role of this 'stickiness' in their biological effects is not known. Here oral squamous carcinoma (OSC2) cells were treated with peroxo-titanates (APT) for $72 \mathrm{~h}$, after which cells were washed several times before the scanning electron image was obtained. The APT particles are retained on the cell surfaces and to some degree on the culture-vessel.

concentrations were increased to $200 \mu \mathrm{g} / \mathrm{mL}$ (Figure 7) resulting in a significant increase in assay interference from $25 \%$ to $100 \%$ for APT and to $55 \%$ for MST. nMST was also tested and found to interfere with OD measurements by $20 \%$ at concentrations of $200 \mu \mathrm{g} / \mathrm{mL}$. Thus, corrections for the particulate appear mandatory.

In spite of some successes, the centrifugation-transfer strategy was not completely effective in correcting the bias to OD measurement; the particulate concentration was too great and centrifugation not efficient enough at sequestering the particulate (Figure 3). In addition, the process of transferring supernatant was time and labor intensive and prone to error.

Two alternative approaches have been used to mitigate the effects of particulate bias in measuring the effects of titanates on cells. The first was to use a NanoDrop Spectrophotometer (Thermo Scientific) to read the OD [16]. Because the NanoDrop ${ }^{\mathrm{TM}}$ uses a $1 \mu \mathrm{L}$ volume to read OD (vs. 50-100 $\mu \mathrm{L}$ for the plate-reader method), and microtitanates settle quickly in solution, the sample from the culture well could be harvested away from the cells and particulates on the bottom of the culture well, and the OD of the solution could be measured with minimal particulate interference (Figure 7). The downside was that each 96-well plate had to be read one well at a time which was time and labor intensive ( $v s$. a microplate reader where 96 wells can be read in 4-5 s). As an alternative, another mitochondrial activity assay, CellTiter-Blue ${ }^{\circledR}$ (CTB; Promega, Madison, WI) which relies on a fluorescent signal rather than on optical density (OD) signal has also been tested [16]. Using CTB to assess cell metabolism, neither MST nor nMST interfered with a fluorescent signal (Figure 7); APT as yet untested). In addition, for two cell lines (OSC2 and WI-38), similar results were obtained using the MTT-NanoDrop ${ }^{\mathrm{TM}}$ method versus CTB [16]. Additionally, the CTB method retains the advantage of rapid reading of multiple wells simultaneously.

When metals were complexed with the titanate particles, particulate interference was variable and dependent on both the metal and the titanate species. Both MST-Au(III) and MST-cis-platin resulted in decreased interference by $\sim 50 \%$ compared to native MST while MST-Pt(IV) interference was not significantly different from native MST interference [16]. Results were similar for interference of nMST-Au(III) with 50\% decreased interference compared to nMST [16]. However, nMST-cis-platin interference was increased compared to nMST (unpublished observations). The authors speculated that absorption of the metal ions to the particles changed the affinity of the particles for the charged surface of the tissue culture plate thus altering how much material is retained during the assay washing steps. The addition of cells to the system did not significantly alter the interference of MST with OD measurements at maximum tested concentrations but did significantly increase the interference of nMST [16]. Use of the CTB system eliminated the interferences entirely.

Titanate interference with OD readings has also been of concern in bacterial studies where the primary method to measure bacterial growth relies on the turbidity (OD) of the solution. Because the titanates and bacteria cannot be separated by centrifugation, alternative strategies have been applied to circumvent the OD interference. One strategy has been to design studies such that working concentrations of titanates remain below $25 \mu \mathrm{g} / \mathrm{mL}$ and thus minimally interfere with OD (Figure 6). A second strategy has been to correct OD measurement of bacteria titanate cultures with titanate only cultures. Both strategies have been successfully applied with the disadvantage of limiting the range of material concentrations that are able to be studied.

Overall, several strategies are currently successfully employed in our lab to measure the biological activity of titanates. However, numerous other potential assay systems exist to potentially assess the biological activity of these materials [19-21] as well as potential mechanisms of action [22].

\section{Titanates vs. Titanium Dioxide}

Both titanates and titanium dioxide $\left(\mathrm{TiO}_{2}\right)$ are oxides of titanium. Currently, $\mathrm{TiO}_{2}$ is widely explored and used in biological contexts 
$[23,24]$ whereas titanates are mostly unknown materials. These materials have many similarities but also a very notable difference in their surfaces. The well-defined crystalline surface and surface groups of titanates result in a material that is an ion exchanger rather than a surface interactor [25]. When considering specific variations of titanates, both MST and APT are also much larger particulates than most $\mathrm{TiO}_{2}$ nanoparticles currently in use. nMST is similar in size to $\mathrm{TiO}_{2}$ but has a large crystalline surface area and relatively little amorphous core. Studies that have focused on the addition of functional groups to the surfaces of $\mathrm{TiO}_{2}$ nanoparticles support the importance of these surface differences [26]. Overall, the biological toxicity of titanium dioxide is complex and varies widely depending on the type of cell tested, the size of the particles, the surface modifications, and the material crystallinity (anatase versus rutile) [27-30]. Similar parameters affect the biological toxicity of titanates and provide potential insight into the in vitro and in vivo compatibility of titanates.

\section{Future Research}

Several avenues of research can be anticipated in the area of titanates for biomedical applications. Although significant progress in characterizing the biologically relevant properties of titanates has been made, $[12,16]$ almost nothing is known about the mechanisms that are responsible for these properties. In the final analysis, it is these mechanisms that will drive the biomedical and environmental utility of these novel compounds. For this reason, future research will likely pursue the various aspects of these mechanisms.

Native titanates suppress mammalian cell metabolism to some extent in several cell types, [2] and some metal ions complexed to titanates further suppress cellular metabolism [3,13,14]. Further experiments will likely investigate the connection between cytotoxicity of native or complexed titanates and the apparent affinity of titanates for cells. Does affinity facilitate transfer of metal ions into cells thereby enhancing the effects of the ions? How is the affinity of titanates to cells mediated and does that affinity vary with the type of cell? Do titanates enter cells prior to releasing metal ions, or do titanates just facilitate entry of metal ions into cells, remaining outside the cell membrane? Why do different titanate-metal compounds have different effects on cell metabolism? These types of questions will figure prominently in the next phase of titanate-mammalian cell research. The answers to these types of questions will form the foundation of understanding the in vivo utility of titanate-metal compounds for applications where mammalian cell metabolism, function, and division are key-- such as in the treatment of cancer, inflammation, or arthritis [15].

For the few bacteria that have been tested, native titanates do not suppress metabolism, but metal-titanate complexes significantly suppress metabolism in cases specific to bacterial species and metaltitanate complex [17]. Here, mechanisms are even more intriguing and more important to understand; the small size of bacteria $(0.2 \mu \mathrm{m})$ vs. the titanates $(5-10 \mu \mathrm{m})$ make it impossible for the titanates to enter the cells. Therefore, research into mechanism will likely focus on the bacteral-titanate interface as a site of facilitated delivery of metal ions from the titanate to the bacteria. The more complex nature of bacterial cell membranes and cell walls will undoubtedly pose a challenge, but is also likely to account for differences in how species of bacteria react to metal-titanate complexes and how one might take advantage of differences to target undesirable species of bacteria. As for mammalian cells, understanding these mechanisms in detail will be paramount to using metal-titanate compounds as antimicrobial agents in any in vivo situation.

\section{Conclusions}

In-vitro evidence to-date suggests that titanates are not toxic to several strains of bacteria, but that they suppress mammalian cell metabolism of several (but not all) cell types by $30-50 \%$ vs. unexposed controls. The reasons for these different cellular reactions are not known but may involve the relative sizes of the particles $v s$. target cells or the ability of the particles to gain access to the cells. Regardless of their native toxicity, titanates appear to have the ability to enhance the effects of metals on cells, bacterial or mammalian, when they are combined with metal ions. Again, the mechanisms are not understood, but it seems likely that the effect is not simply a function of release of a metal ion extracellularly to the target cell. Rather, titanates appear to enhance delivery of metal ions to cells in some way. The particulate nature of titanates, combined with their 'stickiness' for cells and culture vessels, complicates measurement of in-vitro effects whenever optical density-dependent means are used to assess cell status. OD-independent means, such as fluorescence, appear to be better suited to assessing in vitro cellular effects and discerning the true biocompatibility of these materials. Binding of metals and the biological effects of titanates are influenced by the size, shape, and chemical nature of their crystalline surfaces. Future studies will need to identify the mechanisms of biological effects and investigate other possible artifacts of in-vitro measurements. In addition, practical application of these materials will require extensive in vivo testing. However, reports to-date suggest some optimism for these compounds as environmental scavengers or as a new class of drug-delivery vehicle, particularly to bacteria.

\section{Acknowledgments}

The authors thank the following for support of these projects: Department of Restorative Dentistry at the University of Washington (Spencer fund to JCW), the National Institutes of Health (RO1 DE 021373-01 to WOC) and the United States Department of Energy (Grant \#AC717130 to DTH with subcontract to JCW).

\section{References}

1. Nyman M, Hobbs DT (2006) A family of peroxo-titanate materials tailored for optimal strontium and actinide sorption. Chem Mater 18: 6425-6435.

2. Hobbs DT, Messer RL, Lewis JB, Click DR, Lockwood PE, et al. (2006) Adsorption of biometals to monosodium titanate in biological environments. J Biomed Mater Res B Appl Biomater 78: 296-301.

3. Wataha JC, Hobbs DT, Lockwood PE, Davis RR, Elvington MC, et al. (2009) Peroxotitanates for biodelivery of metals. J Biomed Mater Res B Appl Biomater 91: 489-496.

4. Elvington MC, Tosten M, Taylor-Pashow KML, Hobbs DT (2012) Synthesis and characterization of nanosize sodium titanates. J Nanopart Res 14: 1114.

5. Goyer RA (1986) Toxic Effects of Metals. In: Klaassen CD, Amdur MO, Doull J. Toxicology. ( $3^{\text {rd }}$ edn): 582-635.

6. Hambley TW (2007) Developing new metal-based therapeutics: challenges and opportunities. Dalton Trans: 4929-4937.

7. Bruijnincx PC, Sadler PJ (2008) New trends for metal complexes with anticancer activity. Curr Opin Chem Biol 12: 197-206.

8. Kean WF, Kean IR (2008) Clinical pharmacology of gold. Inflammopharmacology 16: 112-125

9. Lemire JA, Harrison JJ, Turner RJ (2013) Antimicrobial activity of metals: mechanisms, molecular targets and applications. Nat Rev Microbiol 11: 371 384

10. McQuitty RJ (2014) Metal-based drugs. Sci Prog 97: 1-19

11. Sengupta J, Ghosh S, Datta P, Gomes A, Gomes A (2014) Physiologically important metal nanoparticles and their toxicity. J Nanosci Nanotechnol 14 : 990-1006.

12. Davis RR, Lockwood PE, Hobbs DT, Messer RL, Price RJ, et al. (2007) In vitro biological effects of sodium titanate materials. J Biomed Mater Res $\mathrm{B}$ Appl Biomater 83: 505-511.

13. Davis RR, Hobbs DT, Khashaba R, Sehkar P, Seta FN, et al. (2010) Titanate particles as agents to deliver gold compounds to fibroblasts and monocytes. J Biomed Mater Res A 93: 864-869.

14. Wataha JC, Hobbs DT, Wong JJ, Dogan S, Zhang H, et al. (2010) Titanates deliver metal ions to human monocytes. J Mater Sci Mater Med 21: 12891295.

15. Drury JL, Chen YW, Wong JJ, Elvington MC, Rutherford RB, et al. (2014) Titanates deliver metal compounds to suppress cell metabolism. J Exp Clin Med 6: 21-27.

16. Drury JL, Jang Y, Taylor-Pashow KM, Elvington M, Hobbs DT, et al. (2015) In vitro biological response of micro- and nano-sized monosodium titanates and titanate-metal compounds. J Biomed Mater Res B Appl Biomater 103: 254-260.

17. Chung WO, Wataha JC, Hobbs DT, An J, Wong JJ, et al. (2011) Peroxotitanate- and monosodium metal-titanate compounds as inhibitors of bacterial growth. J Biomed Mater Res A 97: 348-354.

18. Holder AL, Goth-Goldstein R, Lucas D, Koshland CP (2012) Particle-induced artifacts in the MTT and LDH viability assays. Chem Res Toxicol 25: 18851892 
19. Hillegass JM, Shukla A, Lathrop SA, MacPherson MB, Fukagawa NK, et al (2010) Assessing nanotoxicity in cells in vitro. Wiley Interdiscip Rev Nanomed Nanobiotechnol 2: 219-231.

20. Landsiedel R, Ma-Hock L, Kroll A, Hahn D, Schnekenburger J, et al. (2010) Testing metal-oxide nanomaterials for human safety. Adv Mater 22: 2601-2627.

21. Love SA, Maurer-Jones MA, Thompson JW, Lin YS, Haynes CL (2012) Assessing nanoparticle toxicity. Annu Rev Anal Chem (Palo Alto Calif) 5 181-205.

22. Fröhlich E (2013) Cellular targets and mechanisms in the cytotoxic action of non-biodegradable engineered nanoparticles. Curr Drug Metab 14: 976-988.

23. Visai L, De Nardo L, Punta C, Melone L, Cigada A, et al. (2011) Titanium oxide antibacterial surfaces in biomedical devices. Int J Artif Organs 34: 929-946.

24. Yin ZF, Wu L, Yang HG, Su YH (2013) Recent progress in biomedical applications of titanium dioxide. Phys Chem Chem Phys 15: 4844-4858.

25. Thomas AG, Syres KL (2012) Adsorption of organic molecules on rutile TiO2 and anatase TiO2 single crystal surfaces. Chem Soc Rev 41: 4207-4217.
26. Thevenot $P$, Cho J, Wavhal D, Timmons RB, Tang $L$ (2008) Surface chemistry influences cancer killing effect of TiO2 nanoparticles. Nanomedicine 4: 226-236.

27. Fadeel B, Garcia-Bennett AE (2010) Better safe than sorry: Understanding the toxicological properties of inorganic nanoparticles manufactured for biomedical applications. Adv Drug Deliv Rev 62: 362-374.

28. lavicoli I, Leso V, Fontana L, Bergamaschi A (2011) Toxicological effects of titanium dioxide nanoparticles: a review of in vitro mammalian studies. Eur Rev Med Pharmacol Sci 15: 481-508.

29. Xia T, Hamilton RF, Bonner JC, Crandall ED, Elder A, et al. (2013) Interlaboratory evaluation of in vitro cytotoxicity and inflammatory responses to engineered nanomaterials: the NIEHS Nano GO Consortium. Environ Health Perspect 121: 683-690.

30. Liu K, Lin X, Zhao J (2013) Toxic effects of the interaction of titanium dioxide nanoparticles with chemicals or physical factors. Int J Nanomedicine 8: 25092520. 